\title{
An In Vitro Contraction Model in Mouse Primary Cultured Myotubes Using Satellite Cells Originated from the EDL and Soleus Muscles
}

\author{
YASUKO MANABE*1), SHINYA OGINO*1), MIYUKI ITO*1), YASURO FURUICHI*1), \\ MAYUMI TAKAGI*1), MiO YAMADA*1), NAOKO GOTO-INOUE*1) 2), \\ YUSUKE ONO*3), NOBUHARU L. FUJII*1)
}

\begin{abstract}
*1) Department of Health Promotion Sciences, Graduate School of Human Health Sciences, Tokyo Metropolitan University, Tokyo, Japan, *2) Department of Marine Science and Resources, College of Bioresource Sciences, Nihon University, Kanagawa, Japan, *3) Department of Stem Cell Biology, Atomic Bomb Disease Institute, Graduate School of Biomedical Sciences, Nagasaki University, Nagasaki, Japan
\end{abstract}

Purpose: Skeletal muscle cell lines such as mouse C2C12 cells and rat L6 cells often show abnormal characteristics because of repeated-passage cultures and artificial culture conditions. Primary myotubes are considered to retain their in vivo properties. Here, satellite cells originating from the extensor digitorum longus (EDL) or soleus muscle were differentiated into primary myotubes and used for an in vitro contraction model.

Materials and Methods: Satellite cells from the mouse EDL or soleus were isolated by a single-fiber isolation method. We examined the formation of the sarcomere assemblies by $\alpha$-actininimmunostaining in the differentiated myotubes. We also investigated the contractile characteristics of myotubes stimulated with an electric pulse and insulin induced-glucose uptake. $\mathrm{C} 2 \mathrm{C} 12$ myotubes were used for comparison with the primary myotubes.

Results and Discussion: The sarcomere assemblies were observed in the primary myotubes but hardly observed in the $\mathrm{C} 2 \mathrm{C} 12$ myotubes. The number of myotubes responding to stimulation by the electric pulse was increased in both the $\mathrm{C} 2 \mathrm{C} 12$ and primary myotubes, although the movement in the primary myotubes was larger than that in $\mathrm{C} 2 \mathrm{C} 12$ myotubes. The glucose uptake stimulated by insulin was significantly increased compared to the basal uptake in the primary myotubes and the $\mathrm{C} 2 \mathrm{C} 12$ myotubes. These data suggest that the mouse primary myotubes, with their greater number of sarcomere assemblies and higher level of contractive activity, will be valuable as an in vitro contraction model that can be used in place of cell lines or human primary myotubes.

Key words: skeletal muscle, primary myotubes, contraction

Corresponding author: Nobuharu L. Fujii

Department of Health Promotion Sciences, Graduate School of Human Health Sciences, Tokyo Metropolitan University

1-1 Minami-Osawa, Hachioji-shi, Tokyo 192-0397, Japan

TEL: + 81-42-677-2966 FAX: +81-42-677-2961 E-mail: fujiin@tmu.ac.jp

The $2^{\text {nd }}$ Congress, International Academy of Sportology 〔Held on Sep. 12, 2015〕

〔Received Dec. 18, 2015] 